\title{
Assessing the Quality of the Saudi Healthcare Referral System: Potential Improvements Implemented by Other Systems
}

\author{
Hilal Salim Al Shamsi ${ }^{1}$, Abdullah Ghthaith Almutairi ${ }^{2}$ \& Sulaiman Salim Al Mashrafi ${ }^{3}$ \\ ${ }^{1}$ Directorate of Planning and Studies, Directorate General of Planning and Studies, Al-Buraimi Governorate, \\ Ministry of Health, Oman \\ ${ }^{2}$ Quality Department, Prinice Nasser Hospital, Al-Ghat Province, Ministry of Health, Saudi Arabia \\ ${ }^{3}$ Directorate General of Planning and Studies, Department of Health Information and Statistics, Muscat, Ministry \\ of Health, Oman \\ Correspondence: Hilal Salim Al Shamsi, Directorate of Planning and Studies, Directorate General of Health \\ Services, Al-Buraimi Governorate, Ministry of Health, Oman
}

Received: August 22, 2018 Accepted: September 17, 2018 Online Published: October 13, 2018

doi:10.5539/gjhs.v10n11p113 URL: https://doi.org/10.5539/gjhs.v10n11p113

\begin{abstract}
Introduction: The referral system authorizes and transfers the responsibility for healthcare services from one provider to another. A key component of the system is the communication between primary-care and specialist providers. Poor communication between them is detrimental to and can cause significant issues with coordination of effective care.
\end{abstract}

Objective: The purpose of this review was to evaluate current healthcare referral systems, focusing on the communication among providers, and to suggest practices that could make the Saudi healthcare referral system more effective.

Design: This systematic review identified published studies of the quality of the healthcare referral system in Saudi Arabia and other countries using two databases, Medline and PubMed. Data were summarized and extracted into two tables.

Results: The review included 12 studies that met its selection criteria. These studies were conducted in various regions of Saudi Arabia, but mostly the west and north. The 12 studies included 181,192 participants, with numbers of participants ranging from 21 to 138,484. The present review found that more than $50 \%$ of the referral documents and feedback reports in these studies had incomplete patient information. Implementation of electronic referrals (e-referrals) in several countries, including Australia, New Zealand and the United States, improved their referral systems, particularly by solving the problem of incomplete referral documents. In addition, the present review found that in some specialist clinics, referral cases contributed to increased workloads. One study reported on implementation of Lean Six Sigma principles in a military hospital in western Saudi Arabia, which reduced the number of referrals delayed, inappropriate referrals and the response time to referrals (7\%). E-referrals and Lean Six Sigma principles may be applicable in Saudi Arabia as solutions to referral and response-time problems.

Conclusions: An increase in healthcare referrals in Saudi Arabia has caused an increase in missing essential information in referral letters and feedback reports as well as overcrowding in specialist clinics. The results of the present review suggested that implementing e-referral and Lean Six Sigma principles may improve the quality of Saudi Arabia's healthcare referral system.

Keywords: referral letters, referral system, healthcare, Saudi Arabia, feedback reports, general medical, family practice, hospital, primary healthcare, community medicine

\section{Introduction}

The referral of patients from primary to secondary healthcare settings is a normal, essential aspect of medical practice. Modern healthcare includes close communication and collaboration among various organizations and professional institutions (Vermeir et al., 2015). Written communication has a long history in medical care and is an essential aspect of high-quality care (Nestel \& Kidd, 2004). Currently, little face-to-face communication is conducted among healthcare providers. The most common tool for transferring patient-care information is written 
correspondence (Ramanayake, 2013).

The referral process is an information-intensive one that transfers to another healthcare institution, at either the same level or a higher one, various important demographic and clinical data, including previous diseases, provisional diagnosis, reason for referral, prescriptions, drug allergies, treatments, habits, and clinical questions (Smith \& Khutoane, 2009).

Referrals without sufficient details can cause delayed diagnosis, polypharmacy, discontinuity of healthcare, poor follow-up plans, repeated and unnecessary tests, and the inability of the receiving doctors to identify the need for the referral, all of which can increase medical errors and healthcare costs and decrease quality of care (Smith \& Khutoane, 2009).

Both specialists and general practitioners are attentive to the information regarding their shared patient; however, dissatisfaction has been expressed with the content, timeliness, and volume of this information (Jiwa \& Ward, 2009). Structured referral letters, a strategy to enhance the process of communicating patient information among healthcare providers, are a type of checklist that can guide the referring doctor to include all necessary information in a referral (Stainkey, Seidl, Johnson, Tulloch, \& Pain, 2010).

In Saudi Arabia, the referral system's main role is managing the flow of patient information from the primary to the secondary and tertiary levels of healthcare. This referral system has many problems, including missing information in referral letters. Although the referral system has a long history in the country, no essential improvements have been made to it since its inception. Therefore, the present systematic review was undertaken to evaluate the current healthcare referral system and to identify potential changes that can increase its effectiveness and efficiency.

\section{Methodology}

\subsection{Searches and Data Sources}

First, studies of the quality of the Saudi healthcare referral system were identified. The Medline and PubMed databases were searched using the keywords "referral letters," "referral system," "healthcare," "Saudi Arabia," "feedback reports," "general medical," "family practice," "hospital," "primary healthcare," and "community medicine." The search returned articles that contained these keywords in their titles or abstracts.

\subsection{Inclusion and Exclusion Criteria}

This systematic review included studies and reviews that addressed the quality of the referral letters and feedback reports in the Saudi healthcare system. It excluded non-peer-reviewed articles, studies having response rates of less than $60 \%$, and studies of referrals that did not address their quality. Because few published articles were found on this topic, the search was unlimited regarding the time period of publication.

\subsection{Data Extraction}

The extracted data were summarized in two tables. Table 1 includes the general characteristics of the studies, specifically the region where they were conducted, the types of organizations that conducted them, the study type, the data collection method, the sample size, and the response rate. Table 2 contains the results regarding the quality of the referral letters and feedback reports for each study in the review.

\section{Results}

Figure 1 shows the method used to select the studies eligible for this review. In the first stage, a search of the Medline and PubMed databases returned 1,406 articles. After the duplicates were removed, 794 remained. Next, non-peer-reviewed articles (284) and articles not mainly about healthcare referrals (421) were excluded. Then, studies with response rates of less than $60 \%$ (77) were excluded, leaving 12 articles to be included in this systematic review.

Table 1 shows the general characteristics of the 12 studies included, arranged by the year of publication. Most studies were conducted by institutions in the Ministry of Health (MOH), but four were conducted by institutions related to military healthcare institutes 


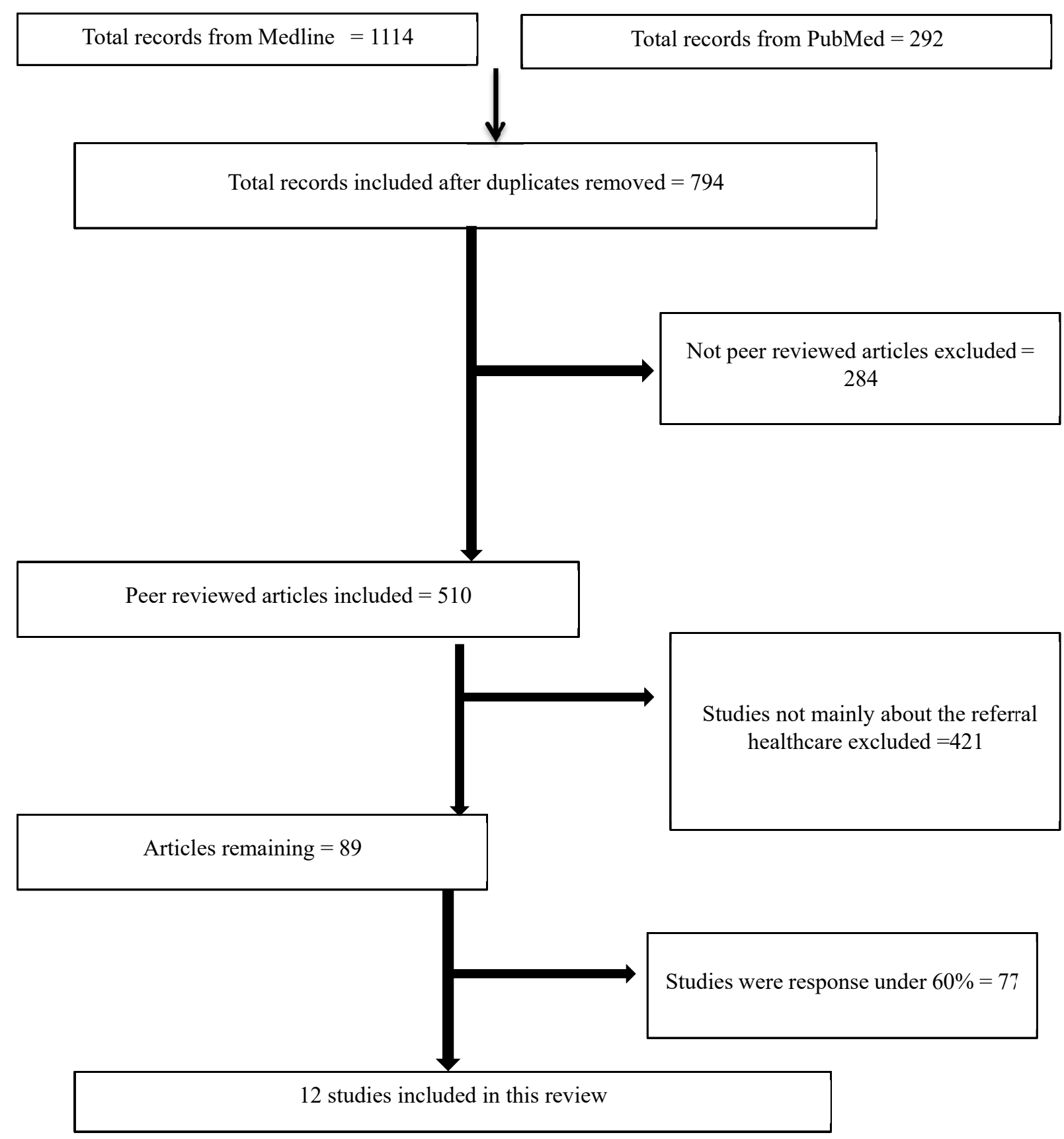

Figure 1. The process of selecting the 12 articles, which are contained in this review

Of the 12 studies, 6 used a cross-sectional design, 4 used a retrospective design, and the remaining 2 were one a review and one case study. In addition, 8 studies collected data from medical records, 3 used questionnaires and one used both medical records and questionnaires. Furthermore, 3 studies were conducted in western Saudi Arabia, 3 in the north, 2 in the south, 1 each in the eastern and central areas of the country, and 2 in 3 locations: central, east, and west Saudi Arabia. The total number of participants in the studies included in the review was 181,192, and the number of participants in each study ranged from 21 to 138,484.

Table 2 shows the topics and most important findings of the 12 studies included in the review. Of the 12, 10 focused on the quality of referral letters and feedback reports, 1 focused on the general quality of primary healthcare, and 1 focused on improvements to the healthcare referral system. The studies' findings can be divided into the following categories: missing information in the referral letters and feedback reports exchanged between primary and secondary healthcare institutions, inappropriate referrals and increasing workloads in some specialist clinics, and ways to improve the healthcare referral system. 
In primary healthcare centers, $5-12 \%$ of outpatient visits resulted in cases being referred to secondary healthcare providers (Al-Kaabba et al., 2010; Al-Qahtani \& Imtiaz, 2004), and the exchange of information between primary and secondary healthcare providers was poor (Abdelwahid, Al-Shahrani, Elsaba, \& Elmorshedi, 2010; Al-Ahmadi $\&$ Roland, 2005). The barriers to the quality of the referral system included inadequate information in both referral letters and feedback reports (Al-Alfi, Al-Saigul, Abed-Elbast, Sourour, \& Ramzy, 2007; Qureshi, Schmidt, Van der Molen, Al-Habeeb, \& Magzoub, 2007). A cross-sectional study in 2010 identified $70.3 \%$ of referral letters and feedback reports as lacking information on the medical advice given, $68.8 \%$ as lacking it on the recommendations given, $54.5 \%$ as lacking examination information, $54.4 \%$ as lacking information on physical examinations, and $44.5 \%$ as lacking medical history (Abdelwahid et al., 2010). Similarly, an older study found information missing in referral letters and feedback reports, including $48.3 \%$ that lacked information on the management plan and $25.2 \%$ that lacked the decisions regarding follow up (Jarallah, 1998). More recent studies have identified missing information regarding diagnoses, vital signs, and the results of clinical examinations and follow-up treatments (Al-Alfi et al., 2007; Al-Kaabba et al., 2010; AlGhamdi, Al-Malki, Nahhas, \& Al-Malki, 2015).

Some specialist clinics receive more referral cases from primary healthcare providers than others (Al-Qahtani \& Imtiaz, 2004). A study conducted in a military hospital in northern Saudi Arabia found that the greatest percentage of referrals $(56.8 \%)$ was received by general surgery, followed by ophthalmology $(17.3 \%)$ and obstetrics and gynecology (14.7\%) (Al-Qahtani \& Imtiaz, 2004). In addition, depending on hospital policies, some procedures can be conducted at the primary healthcare level but should be referred to specialists. Furthermore, one study conducted at 9 primary healthcare centers found that the main reasons for referral were specialized treatment (42.9\%), patient assessment (40.1\%), and the diagnosis of difficult cases (21.4\%) (AlGhamdi et al., 2015).

Between 2014 and 2015, the number of referrals requested of and accepted by secondary healthcare providers increased by $13.6 \%$ and $11.5 \% \%$, respectively, illustrating the necessity of improving the referral system in Saudi Arabia (Alkinaidri \& Alsulami, 2018). In 2018, Alkinaidri and Alsulami (2018) identified the following issues in the Saudi health referral system: delays in responding to referral requests, incomplete referral documents, lack of internal communication consultants, and lack of follow up by coordinators. Therefore, the researchers applied Lean Six Sigma principles to the referral system in King Abdullah Medical City in Makkah. The results included a decrease from $28.1 \%$ to $21.5 \%$ in delayed responses to referral requests, reducing inappropriate referrals and improved compliance with response-time policies (Alkinaidri \& Alsulami, 2018) 
Table 1. Summary of general characteristics of the 12 studies included in this review

\begin{tabular}{|c|c|c|c|c|c|c|c|}
\hline Author & Region & No. Organization & $\begin{array}{l}\text { Type of } \\
\text { Organization }\end{array}$ & Study type & $\begin{array}{l}\text { Data } \\
\text { Collection }\end{array}$ & Sample size & $\begin{array}{l}\text { \% of } \\
\text { response }\end{array}$ \\
\hline (Alkinaidri \& Alsulami, 2018) & Western & $\begin{array}{l}\text { King Abdullah Medical City } \\
\text { in Makkah }\end{array}$ & $\mathrm{MOH}$ & Case study & $\begin{array}{l}\text { Medical } \\
\text { records }\end{array}$ & 16,807 & NA \\
\hline (AlGhamdi et al., 2015) & Western & 9 PHCCs & $\mathrm{MOH}$ & Cross-sectional & Questionnaire & 112 & NR \\
\hline (Albattal, 2014) & Central & $\begin{array}{l}(30 \text { general clinics }) \text { One } \\
\text { PHCCs }\end{array}$ & Military & Cross-sectional & Questionnaire & 51 & $80 \%$ \\
\hline (Al Wadaani \& Balaha, 2012) & Easters & One & $\mathrm{MOH}$ & Cross-sectional & $\begin{array}{l}\text { Medical } \\
\text { records }\end{array}$ & 200 & $100 \%$ \\
\hline (Al-Kaabba et al., 2010) & Northwest & 20 family medicine clinics & Military & Cross-sectional & Questionnaire & 14138 & NR \\
\hline (Abdelwahid et al., 2010) & Southern & one & Military & Cross-sectional & $\begin{array}{l}\text { Medical } \\
\text { records }\end{array}$ & $\begin{array}{l}\mathrm{N}=452 \\
(\text { Female }=269, \\
\text { Male }=183)\end{array}$ & $100 \%$ \\
\hline (Al-Alfi et al., 2007) & Western & Six of PHCCs & $\mathrm{MOH}$ & Cross-sectional & $\begin{array}{l}\text { Medical } \\
\text { records }\end{array}$ & 330 & NA \\
\hline (Qureshi et al., 2007) & Northern & One hospital & $\mathrm{MOH}$ & $\begin{array}{l}\text { Retrospective } \\
\text { study }\end{array}$ & $\begin{array}{l}\text { Medical } \\
\text { records }\end{array}$ & 540 & NA \\
\hline (Al-Ahmadi \& Roland, 2005) & NA & NA & NA & Review & NA & 8,173 & NA \\
\hline (Al-Qahtani \& Imtiaz, 2004) & Northern & One hospital (3 family clinics) & Military & $\begin{array}{l}\text { Retrospective } \\
\text { study }\end{array}$ & $\begin{array}{l}\text { Medical } \\
\text { records }\end{array}$ & 138,484 & NR \\
\hline $\begin{array}{l}\text { (Khattab, Abolfotouh, Al-Khaldi, } \\
\text { \& Khan, 1999) }\end{array}$ & Southern & One PHCC & $\mathrm{MOH}$ & $\begin{array}{l}\text { Retrospective } \\
\text { study }\end{array}$ & $\begin{array}{l}\text { Medical } \\
\text { records }\end{array}$ & 845 & NA \\
\hline (Jarallah, 1998) & $\begin{array}{l}\text { Central; Eastern; } \\
\text { Western }\end{array}$ & $\begin{array}{l}5 \text { hospitals and } 39 \text { health } \\
\text { centers }\end{array}$ & $\mathrm{MOH}$ & $\begin{array}{l}\text { Retrospective } \\
\text { study }\end{array}$ & $\begin{array}{l}\text { Medical } \\
\text { records }\end{array}$ & 1060 & $97 \%$ \\
\hline
\end{tabular}

MOH: The Ministry of Health, NA: Not applicable, NR: Not recorded, PHCCs: Primary Healthcare Centers. 
Table 2. The important finding from 12 studies

\begin{tabular}{|c|c|c|}
\hline Author & Focus & Results \\
\hline \multirow{5}{*}{$\begin{array}{l}\text { (Abdelwahid et al., } \\
\text { 2010) }\end{array}$} & \multirow{5}{*}{ Referral pattern } & High percentage of referrals, although the quality of feedback and referral letter were poor. \\
\hline & & Some absent parts in both feedback and referral letter were found: \\
\hline & & $\begin{array}{l}\text { Investigation in the referral letters }(54.5 \%) \text {, physical examination }(54.4 \%) \text {, patients' medical history }(44.5 \%) \text {, advice given to patient } \\
(70.3 \%) \text {, recommendation }(69.8 \%) \text {, and Investigation }(65.7 \%) \text {. }\end{array}$ \\
\hline & & Overall, Inappropriate referral letter $(12 \%)$ \\
\hline & & Inappropriate feedback (53\%) \\
\hline $\begin{array}{l}\text { (Al-Ahmadi \& } \\
\text { Roland, 2005) }\end{array}$ & Quality of primary care & $\begin{array}{l}\text { The exchange of information between primary and secondary care providers was poor. } \\
\text { - Problems with Referral letters: } \\
\text { often did not include important information, were handwritten, and sometimes illegible. } \\
\text { - Problems with feedback reports: } \\
\text { the sending feedback of patients only } 22-39 \% \text {, lacked details of the advice given (100\%), investigations (21\%) and diagnoses (15\%). }\end{array}$ \\
\hline $\begin{array}{l}\text { (Al Wadaani \& } \\
\text { Balaha, 2012) }\end{array}$ & Referral letters & $\begin{array}{l}\text {-The form was semi-structured. } \\
\text { The absent part in referral letter filled by } \\
\text { 1. consultant: laboratory findings ( } 52.5 \%) \text {, degree of urgency }(75 \%) \text {, clinical findings }(35 \%) \text {. } \\
\text { 2. Specialist: Laboratory findings }(57.7 \%) \text {, degree of urgency }(88.5 \%) \text {. }\end{array}$ \\
\hline $\begin{array}{l}\text { (Al-Alfi et al., } \\
2007)\end{array}$ & $\begin{array}{l}\text { Quality of referral letter } \\
\text { and feedback reports }\end{array}$ & $\begin{array}{l}\text { Referral rate was } 4 \% \text { out the total number of patients seen in PHCCs. The referral letters lacked important information: } \\
\text { History of patient health status ( } 36 \%) \text {, diagnosis }(50 \%) \text {, vital signs }(30 \%) \text {, results of basic investigations }(52 \%) \text {, results of clinical } \\
\text { examination ( } 45 \%) \text {, and treatment which was given in PHCCs }(47 \%) \text {. } \\
\text {-The rate of feedback reports that received by PHCCs was }(30 \%) \text {. The legibility of referral letters }(75 \%) \text { and feedback reports }(63 \%) \text {. } \\
\text { Overall of the quality of: referral letters }(63 \%) \text { and feedback reports }(39 \%) \text {. }\end{array}$ \\
\hline (Albattal, 2014) & inappropriate referrals & $\begin{array}{l}\text { General practices (GP) agreed that the main Factors for making inappropriate referrals: } \\
\text { lack of GP awareness about the available clinics of secondary care }(67.44 \%) \text {, patients 'demands and requests for referral }(83.8 \%) \text {, lack of } \\
\text { specialist referral feedback }(86.04 \%) \text {, and both of the lack of continuity of care in Primary clinics and difficulty with GP-specialist phone } \\
\text { communication in hospital }(90.7 \%) \text {. } \\
\text { The periodic referral auditing on the process between Primary and secondary healthcare is the best management approach for improving } \\
\text { the referral as GPs agreed. }\end{array}$ \\
\hline
\end{tabular}


(Al-Kaabba et al., 2010)

Referral patterns

Imtiaz, 2004)

$\&$

Referrals clinics

(AlGhamdi et al., Rate of referral

2015)

po

$12 \%$ of patients were a referral. A low percentage of feedback from specialists in hospitals (13\%). Also, females $(53.2 \%)$ received more referrals than male. The routine referral was $56 \%$ of the total number of referrals, whereas, the urgent referrals were just $15 \%$. The most referral was to a dermatology clinic (35\%).

About $5 \%$ of outpatient visits in primary healthcare clinics were referral cases to secondary healthcare. The higher referral cases were in general surgery (56.8\%), ophthalmology (17.3\%) and obstetrics and gynecology (14.7\%).

\section{Referral to:}

In General surgery: earlobe piercing for infants account and circumcision

obstetrics and gynecology: simple procedures which can be performed at primary care level but should be referred according to hospital policy

- The main reasons for referral were:

specialized treatment (42.9\%), more assessment of patients (40.1\%), and diagnosis of difficult cases $(21.4 \%)$.

- physicians reported that:

they always issued with feedback (20.8\%), whereas, $53 \%$ of them did have issues with it.

- The area which needs to improve in referral letter and system:

clear typed referral notes (87.5\%), availability of ambulance services $(81.3 \%)$, in-service training for doctors $(94.6 \%)$, in-service training for medical personnel (91.1\%), feedback referral notes $(90.2 \%)$.

(Qureshi et al., $\quad$ Psychiatric referrals
2007)

It found the percentage of filling items of psychiatric referral letters, only: serial number (50.1\%), type of referral (20.9\%), history of patients (47.6\%), physical examination (47.2\%), systemic examination (35.9\%), investigation (21.9\%), given treatments $(30 \%)$.

Increasing total referrals request in 2015 compared to 2014 by $13.6 \%$. Also, increasing total referrals accept in 2015 compared to 2014 by $11.5 \%$.

Some issue in referrals:

(Alkinaidri \& Improving healthcare Inefficiency such as delay in response to the referral, document of referral was incomplete and inappropriate.

Alsulami, 2018) referral system
(35\%) not follow by coordination, (24\%) no internal communication consultant, and (24\%) cross referral.

After applying the Lean Six Sigma project:

the delay in response time of physicians to referral system was reduced. The improvement of compliance to response time from 2.05 (percentage of delayed cases $28.1 \%)$ to $2.2(21.5 \%)$. 
The quality of referral letters was poor $(23 \%)$.

\section{Components of the Referral letters:}

(Jarallah, 1998) Quality of referral letters Physical examination (37.5\%), duration of complaint (52\%), Differential diagnosis (53.8\%). and feedback reports components of the feedback report:

Diagnosis (14\%), Decision on follow up (19.5\%) answering specific questions from PHC doctor (41.7\%) and plan of management $(48.3 \%)$.

The referral rate was 3.8 per 100 patient visits, where feedback was 39.2 per 100 referrals.

inappropriateness of referral letters: Drug history $(0.2 \%)$, present medical history $(2.6 \%)$, results examination $(0.2 \%)$ diagnosis $(25.2 \%)$,

(Khattab et al., Rate and quality of and reason for referral (8.4\%).

1999) referral letters inappropriateness of feedback reports:

finding on examination (5.9\%), finding on investigation (21.9\%), management plan (13.3\%), clear recommendation (10.3\%), Consultants name/ signature (5\%), and summary of history $(6.8 \%)$. 


\section{Discussion}

This review sought to evaluate problems with the current healthcare referral system in Saudi Arabia and to identify potential solutions found by the authors of the 12 studies that met the review's selection criteria. The first problem identified was that in communication between primary and secondary healthcare providers, particularly the absence of some information in referral letters and feedback reports (Table 2). The second problem identified was that cases referred to secondary healthcare providers were concentrated in certain specialist clinics, including general surgery, ophthalmology, and obstetrics and gynecology, which can lead to patient overloads in these types of clinics. Finally, application of Lean Six Sigma principles to the referral system in a military hospital in western Saudi Arabia was found to have improved that system. In brief, the Saudi healthcare referral system has problems that include the communication between primary and secondary healthcare institutions, and those problems may be resolved by applying the results of studies into these same issues.

The Saudi healthcare referral system uses letters and feedback reports as its methods of communicating and exchanging the health-status information of patients referred from primary to secondary healthcare providers. Primary healthcare physicians are responsible for clearly conveying in referral letters the reasons and need for referring patients. In contrast, the specialists in hospitals are responsible for conveying in feedback reports clear information on the health status and management plan of each of his or her patients (AlGhamdi et al., 2015). These processes for handing over patients between general practitioners and specialists at other levels of healthcare are highly variable and potentially risky for patient safety, and the inclusion in the referral of all information needed by the specialist is essential to ensuring timely access to healthcare (Thorsen, 2017). Researchers have found the quality of referral letters and feedback reports in the Saudi healthcare referral system to be poor (Abdelwahid et al., 2010; Albattal, 2014). Other studies have found information missing from both referrals and reports, including information on medical histories, physical examinations, advice and recommendations given, and management plans (Al-Alfi et al., 2007; Jarallah, 1998; Khattab et al., 1999). To ensure patient safety, both referral letters and feedback reports must convey the health status of the patients referred to both general practitioners and specialists.

Electronic healthcare record systems may improve the communication between primary and secondary providers regarding referrals because they have introduced electronic referrals (e-referrals), which enable general practitioners to electronically request referrals to specialist health providers (Naseriasl, Adham, \& Janati, 2015). E-referrals have also been defined as the process of transferring the responsibility for patient care from a referring healthcare provider to a specialist provider and of transferring that responsibility back with the appropriate information in an appropriate timeframe (Tian, 2011). Several countries, including New Zealand, Australia, The Netherlands, the U.K, the United States, and Denmark, have implemented e-referrals to improve the quality of their healthcare referral systems (Naseriasl et al., 2015; Tian, 2011). These nations noted improvements, including reduced wait times; transfer of accurate, complete health information; increased quality of referral communication; and more accurate information about feedback. Therefore, Saudi Arabia could potentially benefit from implementing e-referrals.

The increased number of patients being referred to secondary healthcare providers has increased the burden on some specialist clinics. A retrospective study in Saudi Arabia found that $56.8 \%$ of all referrals from primary healthcare providers went to general surgery clinics, $17.3 \%$ to ophthalmology clinics, and $14.7 \%$ to obstetrics and gynecology clinics, which contributed to patient overloads at these clinics (Al-Qahtani \& Imtiaz, 2004). Likewise, a study in the U.K. reported that the referral of patients to an Ear, Nose and Throat( ENT) emergency department increased its workload by $31 \%$, which led to long wait times and delayed referrals (Mahalingam, Seymour, Pepper, Tostevin, \& Oakeshott, 2014). In brief, referral cases from primary healthcare practitioners increase the workload of certain secondary healthcare clinics in Saudi Arabia.

A military hospital in western Saudi Arabia applied Lean Six Sigma principles to improve its healthcare referral system (Al-Qahtani \& Imtiaz, 2004), which suffered from delayed response to referrals, inappropriate referral cases, and incomplete referral documents. A study in Italy found that inappropriate referrals to emergency departments (EDs) led to ED overcrowding, which in turn increased wait times, delayed referral acceptance, and reduced the quality of the services (Buja et al., 2016). The Lean Six Sigma project improved the referral system to which it was applied by decreasing the delayed in responses by $(5 \%)$, increasing compliance with response-time policies $(79 \%)$, and reducing inappropriate referrals, which in turn reduced overcrowding in clinics (2\%). Lean Six Sigma principles may be appropriate to apply in other countries as a means of reducing the contribution of referrals to the increased workloads in specialist clinics.

This review has a number of strengths. First, some studies included in it were conducted in more than one region of the country. Second, some studies included the results from studies in other countries that addressed the same 
issues. Third, the studies included focused on various aspects of healthcare referrals, which helped to evaluate the system from multiple angles.

\section{Conclusions}

Effective communication between primary and secondary providers is essential to Saudi Arabia's healthcare referral system. This system has some problems, including incomplete referral documents and patient overloads at some specialist clinics due to referrals. The results of other studies that addressed the same problems may potentially improve the Saudi system. The first result that may be applicable was the effectiveness of the e-referral system, which was implemented in several countries, including New Zealand, Australia, and the United States. These e-referral systems provided accurate, complete information about referred patients, indicating that such a system may improve the Saudi system's problem with incomplete referral documents. The second result that may be applicable is Lean Six Sigma principles, which succeeded in reducing inappropriate referrals, thereby decreasing overcrowding in some specialist clinics. Therefore, Lean Six Sigma principles may help to reduce the workload of referral cases in certain specialist clinics in Saudi Arabia. Further studies on these issues are recommended. In addition, the practicability of implementing the e-referral and Lean Six Sigma systems in the Saudi healthcare referral system should be evaluated.

\section{Competing Interests Statement}

The authors declare that there are no competing or potential conflicts of interest.

\section{References}

Abdelwahid, Hassan A, Al-Shahrani, Saeed I, Elsaba, Mohamed S, \& Elmorshedi, Waheed S. (2010). Patterns of referral in the Family Medicine Department in Southeastern Saudi Arabia. Saudi medical journal, 31(8), 925-930.

Al-Ahmadi, Hanan, \& Roland, Martin. (2005). Quality of primary health care in Saudi Arabia: a comprehensive review. International Journal for Quality in Health Care, 17(4), 331-346. https://doi.org/10.1093/intqhe/mzi046

Al-Alfi, M. A., Al-Saigul, A. M., Abed-Elbast, A. M., Sourour, A. M., \& Ramzy, H. A. (2007). Quality of primary care referral letters and feedback reports in Buraidah, Qassim region, Saudi Arabia. Journal of family \& community medicine, 14(3), 113.

Al-Kaabba, A. F, Abdalla, A. M., Saeed, A. A., AlZalabani, A. H., Ahmad, H. H., \& Mustafa, A. A. (2010). Referral patterns of military family medicine clinics in Tabuk, Saudi Arabia. Middle East Journal of Family Medicine, 7(10), 3-12.

Al-Qahtani, D. A., \& Imtiaz, M. L. (2004). An analysis of referrals from primary care. Saudi medical journal, 25(5), 671-672.

Al Wadaani, H. A. A., \& Balaha, M. H. (2012). Evaluation of medical consultation letters at King Fahd Hospital, Al Hufuf, Saudi Arabia. Pan African Medical Journal, 12(1).

Albattal, S. M. (2014). Management of inappropriate referrals in Wazarat health center, Riyadh, Saudi Arabia. International Journal of Medical Science and Public Health, 3(3), 269-276. https://doi.org/10.5455/ijmsph.2013.141220131

AlGhamdi, O. M., Al-Malki, B. M., Nahhas, A. E., \& Al-Malki, A. D. (2015). Rate of referral from primary health care to secondary health care among governmental hospitals in Taif governorate, KSA. International Journal of Medical Science and Public Health, 4(10), 1457-1463. https://doi.org/10.5455/ijmsph.2015.19062015302

Alkinaidri, A., \& Alsulami, H. (2018). Improving Healthcare Referral System Using Lean Six Sigma. American Journal of Industrial and Business Management, 8(02), 193. https://doi.org/10.4236/ajibm.2018.82013

Buja, A., Toffanin, R., Rigon, S., Sandonà, P., Carrara, T., Damiani, G., \& Baldo, V. (2016). Determinants of out-of-hours service users' potentially inappropriate referral or non-referral to an emergency department: a retrospective cohort study in a local health authority, Veneto Region, Italy. BMJ open, 6(8), e011526. https://doi.org/10.1136/bmjopen-2016-011526

Jarallah, J. S. (1998). Referral from primary care to hospitals in Saudi Arabia: 1) quality of referral letters and feedback reports. Journal of family \& community medicine, 5(2), 15.

Jiwa, M., \& Ward, P. R. (2009). Will the need for effective communication between doctors redefine primary care? Mahalingam, Sridhayan, Seymour, Nicola, Pepper, Christopher, Tostevin, Philippa, \& Oakeshott, Pippa. 
(2014). Reducing inappropriate referrals to secondary care: our experiences with the ENT Emergency clinic. Qual Prim Care, 22, 251-255.

Khattab, Maged S, Abolfotouh, Mostafa A, Al-Khaldi, Yahia M, \& Khan, Mohamed Y. (1999). Studying the referral system in one family practice center in Saudi Arabia. Ann Saudi Med, 19(2), 167-170. https://doi.org/10.5144/0256-4947.1999.167

Naseriasl, M., Adham, D., \& Janati, A. (2015). E-referral solutions: successful experiences, key features and

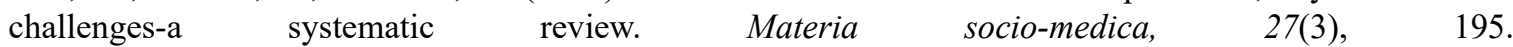
https://doi.org/10.5455/msm.2015.27.195-199

Nestel, D., \& Kidd, J. (2004). Teaching and learning about written communications in a United Kingdom medical school. Education for health (Abingdon, England), 27. https://doi.org/10.1080/13576280310001656169

Qureshi, N. A., Schmidt, H. G., Van der Molen, H. T., Al-Habeeb, T. A., \& Magzoub, M. E. (2007). Quality of psychiatric referrals in Saudi Arabia. Neurosciences, 12(1), 53-61.

Ramanayake, R. P. J. C. (2013). Structured printed referral letter (form letter) saves time and improves communication. Journal of Family Medicine and Primary Care, 2(2), 145-148. https://doi.org/10.4103/2249-4863.117404

Smith, S., \& Khutoane, G. (2009). Why doctors do not answer referral letters. South African Family Practice, 51(1). https://doi.org/10.1080/20786204.2009.10873810

Stainkey, L. A., Seidl, I. A., Johnson, A. J., Tulloch, G. E., \& Pain, T.. (2010). The challenge of long waiting lists: how we implemented a GP referral system for non-urgent specialist'appointments at an Australian public hospital. BMC health services research, 10(1), 303. https://doi.org/10.1186/1472-6963-10-303

Thorsen, O. (2017). General practitioners' referrals to specialist health services. Exploring elements and factors in the referral process having an impact om patients' access to specialty care.

Tian, L. (2011). Improving knowledge management between primary and secondary healthcare: an e-referral project. Health Care and Informatics Review Online, 15(1), 31-37.

Vermeir, P., Vandijck, D., Degroote, S., Ommeslag, D., Van De Putte, M., Heytens, S., . . Vogelaers, D. (2015). Mutual perception of communication between general practitioners and hospital-based specialists. Acta Clinica Belgica, 70(5), 350-356. https://doi.org/10.1179/2295333715Y.0000000032

\section{Copyrights}

Copyright for this article is retained by the author(s), with first publication rights granted to the journal.

This is an open-access article distributed under the terms and conditions of the Creative Commons Attribution license (http://creativecommons.org/licenses/by/4.0/). 